\title{
LA DIFICIL SITUACIÓN DE SER PERSONA ADULTA MAYOR EN EL PERÚ EN TIEMPOS DE PANDEMIA*
}

\author{
THE DIFFICULT SITUATION OF BEING AN ELDERLY PERSON IN PERU IN \\ TIMES OF PANDEMIC
}

\author{
Mágaly Rosaura Arredondo Bastidas**
}

\begin{abstract}
RESUMEN: El presente artículo tiene por objetivo revisar y cuestionar algunos conceptos tradicionales cuando se aborda la temática de las personas adultas mayores, con la finalidad de analizar de manera cronológica y desde una perspectiva de derechos humanos, la normatividad legal que dispuso y prorrogó la cuarentena focalizada en tiempos ${ }^{1}$ de pandemia a causa del COVID-19.

Sustentando que las medidas legales adoptadas fueron discriminatorias por razón de edad, no sólo significando la privación del derecho a la libertad de tránsito, sino que además afectó otros derechos humanos y libertades fundamentales. Finalmente se presenta las voces de algunas personas mayores que manifiestan su percepción sobre el tema.
\end{abstract}

ABSTRACT: The purpose of this article is to review and question some traditional concepts when addressing the issue of elderly adults, in order to analyze chronologically and from a human rights perspective, the legal framework that established and extended the quarantine focused on times of pandemic due to COVID-19. Sustaining that the legal measures adopted were discriminatory for reasons of age, not only meaning the deprivation of the right to freedom of movement, but also affected other human rights and fundamental freedoms. Finally, the voices of some elderly people who express their perception on the subject are presented.

PALABRAS ClAVE: Persona adulta mayor, sujeto de derecho, vejez, envejecimiento, autonomía.

KEYWORDS: Elderly person, subject of law, old age, ageing, autonomy.

Fecha de recepción: $31 / 10 / 2020$
Fecha de aceptación: $31 / 10 / 2020$

doi: https://doi.org/10.20318/universitas.2021.6197

\footnotetext{
* (Mi agradecimiento a las 154 personas adultas mayores que brindaron su tiempo para el llenado de las encuestas para este trabajo, que me permitió un mejor panorama y valiosa información)

** Abogada. Magister del Máster Universitario en Estudios Avanzados en Derechos Humanos por la Carlos III de Madrid. Magister en Gerencia Pública por la EUCIM Business School. Experiencia laboral en la Universidad Carlos III de Madrid en España y Perú en los ministerios de: Educación, Desarrollo e Inclusión Social, Relaciones Exteriores y como asesora de la Gerencia Central de la Persona Adulta Mayor y Persona con Discapacidad del Seguro Social de Salud - EsSalud. Miembro del Ilustre Colegio de Abogados de Lima y directora ejecutiva de AIBIDNA.

E-mail: magarredondo@gmail.com
} 


\section{1.- INTRODUCCIÓN}

La pandemia desatada en el mundo por el COVID-19 evidenció y acrecentó distintos problemas estructurales por el que atravesamos como sociedad global. Se comprobó que la vulnerabilidad es una condición propia en la vida de la persona, y que la situación de vulnerabilidad se agrava cuando recae en grupos menos favorecidos, siendo uno de los más afectados las personas adultas mayores ${ }^{2}$ por ser denominadas como "grupo de riesgo" y por ende como si estuvieran destinados a fenecer. Esta situación descrita no ha sido ajena en el Perú.

Considerando lo anterior, este trabajo pretende demostrar la discriminación por edad ${ }^{3}$ amparada por diferentes dispositivos legales que dispusieron y prorrogaron la cuarentena focalizada que vivieron las personas adultas mayores en el Perú, incrementando sin duda la situación de vulnerabilidad en el que día a día se desarrollan, y dentro de un marco de estereotipos que existen referente al envejecimiento.

Respecto a la metodología, atendiendo al objetivo trazado se utilizó el método sistémico enmarcado de un lado por el análisis jurídico y documental que abarca la revisión de bibliografía relevante en la materia, el análisis normativo, informes procedentes de organismos internacionales, entre otros; y de otro lado, investigación de campo a través de la recogida de datos mediante una encuesta.

\section{2.- ALGUNAS CUESTIONES PREVIAS SOBRE CONCEPTOS QUE PERMITA ENTENDER LA SITUACIÓN DE VULNERABILIDAD DE LA PERSONA ADULTA MAYOR}

\section{1.- Vejez}

En el Perú hablar de vejez atañe a la categoría de "ser viejo vieja" y con ello se asume la pertenencia a un grupo social

\footnotetext{
2 Ley de la Persona Adulta Mayor No 30490 Act 2016, (LPAM 2016). (Se emplea la denominación persona adulta mayor por ser legalmente reconocida en el Perú, Así como, en la Convención interamericana sobre la protección de los derechos humanos de las personas mayores, sin perjuicio de incluir los términos de personas con edad avanzada o personas mayores).

3 Convención Interamericana sobre la protección de los derechos humanos de las personas mayores (adoptada 15 de junio 2015) A-70 (CIDHPM 2015) <http://www.oas.org/es/sla/ddi/tratados_multilaterales_interamericanos_a-

70_derechos_humanos_personas_mayores.asp > Última fecha de acceso 26 febrero 2021. (Cualquier distinción, exclusión o restricción basada en la edad que tenga como objetivo o efecto anular o restringir el reconocimiento, goce o ejercicio en igualdad de condiciones de los derechos humanos y libertades fundamentales en la esfera política, económica, social, cultural o en cualquier otra esfera de la vida pública y privada).
} 
inmediatamente luego de cumplir 60 años de edad, ${ }^{4}$ esta idea fue reforzada en la pandemia cuando se catalogó a todas las personas de 60 y más años como un grupo de riesgo. Y es que la vejez en un contexto de pandemia acrecentó los cambios físicos y psicológicos, implicando dependencia económica y funcional, cambios de roles dentro de la sociedad y la familia, la exclusión del mercado laboral, nueva autopercepción y la percepción de los otros a nosotros, ${ }^{5}$ situación que conlleva a la falta de goce y ejercicio de derechos de la persona a quién la sociedad denomina "viejo - vieja".

Se olvida la sociedad que edad avanzada no significa necesariamente vejez. Es así como las autoras ARBER y GINN, ${ }^{6}$ señalan que para hablar de vejez se debe distinguir entre tres sentidos diferentes de edad y sus interrelaciones en un contexto sociocultural y de relaciones de género. Defienden la existencia de una edad cronológica, ${ }^{7}$ edad social $^{8}$ y edad fisiológica. ${ }^{9}$ Para la sociedad, será el componente de la edad el que determina la dependencia de las personas adultas mayores frente al grupo de personas que no lo son, ${ }^{10}$ llegando incluso a despojarlas de decidir sobre su propia vida a medida que avanza "su edad".

4 LPAM 2016; Cécile Blouin, Erika Tirado Rao y Francisco Mamani Ortega (eds), La
situación de la población adulta mayor en el Perú: camino a una nueva política
(Pontificia Universidad Católica del Perú Instituto de Democracia y Derechos
Humanos
2018) <http://repositorio.pucp.edu.pe/index/handle/123456789/133591> Última fecha de acceso 09 enero 2021. (Los autores señalan que la vejez es una etapa que se caracteriza por la interacción entre la sociedad en sí misma y las personas que llegan a una determinada edad que las hace ser consideradas poco activas).

5 Miguel Villa y Luis Rivadeneira, 'El proceso de envejecimiento de la población en América Latina y el Caribe: una expresión de la transición demográfica' (Conferencia encuentro latinoamericano y caribeño sobre las personas de edad, Santiago de Chile, 8-10 setiembre 1999) <https://repositorio.cepal.org//handle/11362/34671> Última fecha de acceso 11 enero 2021.

6 Sara Arber y Jay Ginn, Relación entre género y envejecimiento: Enfoque sociológico (Narcea Ediciones 1996). Las autoras señalan que existen distintos significados de edad.

7 Implica la edad calendario, aquella edad que se cumple cada año, genera cambios de posición en la sociedad dada las responsabilidades y privilegios que dependen de la edad cronológica. En el caso del Perú la Constitución política señala la edad mínima para ser presidente de la república, el Código Civil señala la edad mínima para casarse, la legislación electoral la edad para votar, la legislación laboral y jubilatoria regula la edad para jubilarse, entre otros.

8 Conjunto de actitudes y conductas que construye la sociedad conformada por la autopercepción de la persona con su edad, la edad que la sociedad le atribuye a la persona y las vicisitudes a lo largo de su vida. Las autoras reafirman que la edad social ha servido para justificar la jubilación fundada en la edad cronológica.

${ }^{9}$ Se relaciona con los cambios en la capacidad funcional del cuerpo, las capacidades sensoriales y motrices, entre otros.

10 John Williams, 'An International Convention on the Rights of Older People?', Emerging Areas of Human Rights in the 21st Century: The Role of the Universal Declaration of Human Rights (Routledge ed, 2011). 
Respecto de la vejez ARANIBAR señala que es una condición que varía y seguirá transformándose en el tiempo, de acuerdo al momento histórico, cultural, factores socioeconómicos, género, etnia y lugar de residencia. ${ }^{11}$ Siendo que los estudios realizados se han enfocado en tratar de "resolver el problema" del envejecimiento y la vejez y no abordarlo desde un enfoque integral que permita definirlo en toda la magnitud y complejidad que representa.

Por ello PEREZ, ${ }^{12}$ propone que, aunque existan diferentes concepciones de la vejez, ${ }^{13}$ estas deberán incluir la edad y la estructura o sistema social. La edad, como una gran variable para entender la vejez; y, la estructura o sistema social como la imposición de pautas de comportamiento y conductas impuestas por la sociedad que crea la vejez. ${ }^{14}$ Entonces, "existiría el concepto de edad [y por lo tanto de vejez] porque la estructura social lo desea (...) edad y sociedad se contienen una a la otra delimitando el terreno donde surge con propiedad el fenómeno social de la vejez". ${ }^{15}$ Asimismo, la autora afirma que aunque distintos serían las dimensiones de la edad y vejez, suelen ser confundidos entre sí, por lo que es necesario presentar algunas teorías que defienden cada una de las variables, debido que esas concepciones se ven plasmadas en la elaboración de los dispositivos legales que dispusieron y prorrogaron la cuarentena focalizadas para las personas adultas mayores en el Perú.

\subsection{1. - Teorías que platean la edad como criterio orientador para la} construcción de un concepto de vejez

En un primer momento se presenta la teoría de la modernización, sostiene que a medida aumenta el grado de modernización de las sociedades, disminuye la valoración social de la vejez. ${ }^{16}$ Intenta homogeneizar a través de una teoría general que explica la conducta de "los viejos - las viejas" y de la sociedad hacia

11 Paula Araníbar, Acercamiento conceptual a la situación del adulto mayor en América Latina (CEPAL, 2001) 8 <https://repositorio.cepal.org//handle/11362/7157> Última fecha de acceso 20 noviembre 2020.

12 Lourdes Pérez Ortiz, Las necesidades de las personas mayores en España: vejez, economía y sociedad (Madrid Editores, 1998)

<https://dialnet.unirioja.es/servlet/libro?codigo=239693> Última fecha de acceso 15 diciembre 2020.

13 San Roman Teresa, Vejez y cultura hacia los límites del sistema (2da edición, 1990); Arber y Ginn (n 5); María-Teresa Bazo, La sociedad anciana (Centro de Investigaciones Sociológicas, 1990); Pilar Rodríguez, 'Investigación-Acción Participativa Como Estímulo a La Participación de Las Personas Mayores' [1995].

${ }^{14}$ Pedro Olivares-Tirado, 'Dependencia de Los Adultos Mayores En Chile' ( Departamento de Estudios y Desarrollo SIS- Superintendencia de Salud, marzo 2008) <https://www.supersalud.gob.cl/documentacion/666/articles-

4471_recurso_1.pdf> Última fecha de acceso 27 diciembre 2020.

15 Pérez Ortiz (n 11) 21.

16 Paula Aranibar (n 10) 13. 
ellos. Los detractores de esta concepción señalan que está olvidando la diversidad social, cultural, económica, entre otras.

Una segunda perspectiva, es la teoría generacional y cohorte, ${ }^{17}$ cada vez que se cumplen años existen un cambio de roles y acumulación de conocimientos, es decir a medida que aumentan años cronológicos existen cambios biopsicosociales en las personas que viven $y$ se desarrollan dentro de contextos de experiencias históricas, ${ }^{18}$ y en la interrelación de los conflictos entre generaciones, se tienden a resolver en beneficio de las generaciones más jóvenes sobre las "más viejas" 19 evidenciando la existencia de un grupo dominante sobre un grupo dominado.

Una tercera postura es la teoría de ciclo de vida, nos acerca a la noción que la situación y la posición social de la vejez están determinadas por los acontecimientos, decisiones y conductas de los individuos en etapas anteriores de la vida de la persona ${ }^{20}$. Defiende que la vejez se suscribe como una etapa más en el proceso total del ciclo vital, y no como una ruptura del tiempo ni mucho menos a una etapa final de la vida.

2.1.2.- Teorías que platean los sistemas o estructuras sociales como criterio orientador para la construcción de un concepto de vejez.

Un primer acercamiento se aprecia en la teoría de la subcultura, ${ }^{21}$ propuesta a mediados de la década de 1960 por Rose, señala que el agrupamiento por edades que realiza la sociedad conduce inevitablemente hacia la formación de una subcultura, y es esta la que define y dirige la conducta de sus miembros, por lo que sobrepasar una determinada edad se constituirían en una minoría. En la que además se establecería la teoría del etiquetaje (labeling) que afirma que "el grupo de viejos" responde más a una identidad

17 ibid. (Señala que cohorte de nacimiento son las personas nacidas aproximadamente al mismo tiempo, puede aludir al grupo de individuos que envejecen en etapas históricas específicas.)

18 Paula Araníbar (n 10); Lourdes Pérez Ortiz (n 11) 27. (Atañe a que el fenómeno generacional y de pertenencia a una generación se enlaza en cuatro componentes: La del dato biológico (el año de nacimiento), la posición generacional (comparten un mismo entorno sociohistórico), la conexión generacional (vinculación concreta de los individuos) y la unidad generacional (fusionar las experiencias individuales en una unidad superior, "una generación para si", siendo posible encontrar en una generación varias unidades generacionales).

19 Paula Aranibar ( $n$ 10) 14. (Existe un error al pensar que los jóvenes de hoy experimentaran su vejez con los mismos problemas y de la misma forma que lo experimentan los "actuales viejos").

20 ibid.

${ }^{21}$ Arnold M Rose, 'The Subculture of the Aging: A Framework for Research in Social Gerontology' [1965] 8-16. 
impuesta por la sociedad que a un proceso de autoidentificación siendo que la etiqueta condicionará su conducta en la sociedad. ${ }^{22}$

Una segunda perspectiva es la teoría de la adaptación social ${ }^{23}$ que se aproxima a la vejez como fenómeno social, y es la eficiente adaptación del individuo al medio social lo que le permitirá desarrollar sus capacidades y habilidades personales para satisfacer sus necesidades y aprovechar sus oportunidades. ${ }^{24}$

Al amparo de esta concepción se elabora la controvertida teoría del retraimiento o desvinculación sostiene que la vejez genera disminución de la interacción entre el individuo y la sociedad, porque el individuo se desprende de roles y responsabilidades sociolaborales y asume la búsqueda de encontrar un espacio de paz y preparación para la muerte. ${ }^{25}$ Como contrapartida surge la teoría de la actividad, señalando que la desvinculación del individuo es producto de la falta de oportunidades de la sociedad y no un proceso que la persona desee, ${ }^{26}$ debido que si la persona mantienen las actitudes y actividades habituales por el máximo tiempo posible, entonces un envejecimiento satisfactorio consiste en permanecer como en la edad adulta. ${ }^{27}$ Profundizando el enfoque de la adaptación, nace la teoría del vaciado de roles, consiste en la perdida de roles y de las normas generando pérdida de noción de lo correcto o incorrecto en el ámbito de su conducta social. 28

Un postulado como muchos adeptos es la teoría de la dependencia estructurada o gerontología crítica $^{29}$ refiere que la vejez es más una construcción social que un fenómeno psicobiológico y son los condicionantes sociales, económicos y políticos los que determinan y conforman las condiciones de vida y las imágenes sociales de las personas mayores. ${ }^{30}$ Situación social construida, en base a la división del trabajo y de la estructura de desigualdad

22 Paula Aranibar (n 10) 16. (En ese contexto, las personas "etiquetadas" con decrepitud, dependencia, enfermedad y terminará asumiendo estas características como propias).

23 (Coinciden con el inicio de la década de 1950, bajo el claro dominio de los paradigmas funcionalistas y conductistas. A su vez brinda el marco para que se desarrollen las teorías de desvinculación, de la actividad y del vaciado de roles).

24 Pérez Ortiz ( $n$ 11).

25 Rodríguez (n 12).

26 Paula Aranibar (n 10) 16.

27 Bazo (n 12) 10.

28 Paula Aranibar (n 10) 16.

29 Mike Bury, Envejecimiento, Género y Teoría Sociológica en Relación Entre Género y Envejecimiento (Narcea Ediciones, 1996) 33-54. (La Teoría de la gerontología crítica surge a fines de la década de 1970, cuando los efectos de la crisis del petróleo pusieron en tela de juicio el mantenimiento del Estado de bienestar en Europa); Sara Arber y Jay Ginn (n 5); Víctor Alba, Historia Social de La Vejez (Laertes Editorial, 1992); Víctor Alba, Paro y jubilación, envejecimiento prematuro en Gerontología y salud: perspectivas actuales (Biblioteca Nueva, 1997) 59-76. $<$ https://dialnet.unirioja.es/servlet/articulo?codigo $=2089450>$ Última fecha de acceso 27 febrero 2021.

30 Rodríguez (n 12). 
existente en toda sociedad y en todo momento. ${ }^{31}$ Por lo cual, desde este enfoque, los beneficios de una política social "generosa" originan una serie de

estereotipos negativos sobre la vejez, 32 al amparo de la dependencia de la sociedad, que le entrega beneficios "a cambio de nada". 33 34 Las críticas a esta teoría señalan que esta construcción es un enfoque que al estar orientada desde una visión externa de la persona, niega la posibilidad de las acciones de los colectivos o del activismos gerontológico. Asimismo, la constante reiteración de la relación de adulto mayor con dependencia, pobreza, categoría inferior, supondría reforzar los estereotipos y la autopercepción de la visión de "las mujeres ancianas más pobres", aunque la intención sea la reivindicación de su perfil político. ${ }^{35}$

Por lo expuesto, no existe un único significado consensuado e integrador de vejez, debido a su componente heterogéneo, dinámico y diverso. Sin embargo, podemos afirmar que considerar la edad, como punto central que defina la vejez, sólo permite perpetuar la discriminación por razón de edad que padecen a diario las personas adultas mayores, atribuyéndoles a ellas la causa del "problema de la vejez"; por tanto, refuerza la relación de asimétrica entre la sociedad y personas adultas mayores; además, justifica los abusos del poder enmascarado en una "protección social" muchas veces inexistente. Asimismo, desde el punto de vista de las teorías que privilegian únicamente la construcción social sobre la edad, corren el riesgo de ofrecer una mirada homogenizadora, universal y atemporal de la vejez, olvidando los factores sociales, culturales, económicos e individuales de cada persona; valdría la pena recordar que los problemas que afrontan los diferentes grupos de personas adultas mayores hoy, no fueron los mismos que afrontaron en el siglo pasado, ni serán los mismos que afrontaran en el siglo venidero. En ese sentido, contribuiría a la elaboración de la definición de vejez desplazar "el problema" desde el individuo de edad avanzada hacia la sociedad, lo que supondría concentrarse en los obstáculos sociales y

\footnotetext{
31 Paula Araníbar (n 10); Lourdes Pérez Ortiz (n 11). (Considera que este status fue construido y legitimado como consecuencia de las exigencias del capitalismo).

32 Robert Butler, 'Age-Ism: Another Form of Bigotry' en The Gerontologist (1969) 243-246. (En 1969 señala que "viejismo" son las prácticas sociales, costumbres, políticas y ejercicio de derechos, basados en ideas falsas sobre la vejez que generan prejuicios negativos).

33 Paula Aranibar ( $\mathrm{n} 10$ ) 16. Asimismo, respecto al carácter ambivalente de la jubilación como derecho e imposición del despojo de roles sociales véase, Alba, 'Paro y jubilación, envejecimiento prematuro' (n 28).

34 Arber y Ginn ( $n$ 5). (Quienes manifiestan que la diferenciación estructural profunda que implica la condición sexual de las personas, durante el largo de la vida y también influye durante la vejez).

${ }^{35}$ Bury (n 28) 40.
} 
no en el funcionamiento de la persona, criterio que ya se estableció en el caso de las personas con discapacidad. 36

\section{2.- Envejecimiento}

El envejecimiento como proceso biopsico-histórico-social también es dinámico y heterogéneo"37 debe ser entendido no sólo como un proceso al interior del ciclo vital. 38 En ese sentido el envejecimiento poblacional debe considerarse como un fenómeno global y multigeneracional ${ }^{39}$ que implica cambios demográficos, económicos, socioculturales, en el mundo jurídico ${ }^{40}$ y por supuesto en el estudio de los derechos humanos.

Considerar el proceso de envejecimiento sólo desde un aspecto cronológico, aunado a un componente funcional del cuerpo y mente capaz a los parámetros de la sociedad, en complicidad con las barreras sociales que se impone a la persona mayor sólo sirve para perpetuar y justificar la violación de derechos humanos a las personas adultas mayores e invisibiliza el "problema del envejecimiento", el mismo que no radica en la persona mayor, el mismo radica en la sociedad.

En ese contexto en el Perú el envejecimiento de la población, como incremento del número de personas de 60 años a más, muestra un crecimiento permanente debido al descenso de la fecundidad; ${ }^{41}$ y al aumento de la esperanza de vida como un proceso constante y continuo impulsado por los avances tecnológicos y las ciencias médicas, por ejemplo: en el periodo 2015-2020 la esperanza de vida fue de 75,3 años, proyectándose que entre 2045 y 2050 será de 82,1 años, y luego en el periodo 2095-2100 se extendería a 88,1 años. ${ }^{42}$

\footnotetext{
${ }^{36}$ Xabier Etxeberria, La condición de ciudadanía de las personas con discapacidad intelectual (Universidad de Deusto, 2008).

37 Paulina Osorio, La Longevidad: Más Allá de La Bibliografia. Aspectos

Socioculturales' (Universidad del País Vasco, 2006)

<https://www.redalyc.org/pdf/765/76500603.pdf> Última fecha de acceso 26

febrero 2021.

38 ibid 11.

39 George Leeson, 'Prepared or Not, Latin America Faces the Challenge of Aging. Current History: Journal of Contemporary World Affairs' (Current History, febrero 2011) 75-80<https://www.ageing.ox.ac.uk/files/CurrentHistoryMarch\%20201.pdf> Última fecha de acceso 27 febrero 2021.

40 María Isolina Dabove, 'Derecho y Multigeneracionismo: o los nuevos desafíos de la responsabilidad jurídica familiar en la vejez' en Revista de Derecho de familia [2008] 39-54.

41 United Nations, 'World Population Prospects' (Population Division United Nations, 2009 <https://population.un.org/wpp/> Última fecha de acceso 26 febrero 2021.

42 ibid 40.
} 
Así mismo, el Instituto Nacional de Estadística e Informática (INEI), 43 señala el aumento de la proporción de la población adulta mayor de $5,7 \%$ en el año 1950 a 12,7\% en el año 2020, es decir 4 140,000 personas de 60 a más años son adultas mayores de la población total peruana, siendo que $52,4 \%$ son mujeres ( 2 millones 168 mil) y $47,6 \%$ son hombres ( 1 millón 973 mil), de igual modo en el proceso de envejecimiento según avanzan los años ("y se incrementan las barreras sociales"), 44 la proporción de personas con discapacidad va aumentando, as"i se constata un mayor numero de personas adultas mayores con discapacidad, 45 siendo la tasa de prevalencia de discapacidad más alta en las mujeres que en los hombres. ${ }^{46} \mathrm{Se}$ aprecia entonces que existe un grupo dentro de la población adulta mayor, más expuesto a la discriminación múltiple ${ }^{47}$ por lo que, a la luz de la Convención internacional sobre la protección de los derechos humanos de las personas mayores, en adelante la Convención, el derecho a igualdad y no discriminación por razones de edad exige a los Estados que las leyes, políticas públicas y planes contemplen las condiciones específicas y heterogéneas de estos grupos con la finalidad que permita garantizarles el goce y ejercicio de sus derechos. 48

\section{3.- Sujetos de derechos y no sujetos u objetos de protección}

La denominación persona adulta mayor es entendida como "aquella persona que se encuentra en la etapa posterior a la adultez". 49 En el caso peruano, se considera como referencia el valor numérico específico de 60 años a más.

En el ámbito internacional, el artículo 2 de la Convención define como aquella de 60 años o más, salvo que la ley interna determine una edad base menor o mayor, siempre que esta no sea superior a los 65 años.

\footnotetext{
${ }^{43}$ Instituto Nacional de Estadística e Informática, 'Nota de Prensa' (INEI, 25 agosto 2020) <http://m.inei.gob.pe/prensa/noticias/en-el-peru-existen-mas-de-cuatromillones-de-adultos-mayores-12356/> Última fecha de acceso 26 febrero 2021. 44 (Agregado entre comillas nuestro).

45 Sandra Huenchuan, Envejecimiento, Personas Mayores y Agenda 2030 para el Desarrollo Sostenible: Perspectiva Regional y de Derechos Humanos (Naciones Unidas ed, 2019) $73<$ https://www.unilibrary.org/content/books/9789210586405> Última fecha de acceso 26 febrero 2021.

${ }^{46}$ Comisión económica para América Latina y el Caribe, 'Panorama social da América latina 2012' (documento informativo) 2012. <https://repositorio.cepal.org//handle/11362/1246> Última fecha de acceso 26 febrero 2021.

47 CIDHPM 2015, art. 2 (n 2). (Cualquier distinción, exclusión o restricción hacia la persona mayor fundada en dos o más factores de discriminación).

48 ibid. art. 5.

${ }^{49}$ Blouin, Tirado Rao y Mamani Ortega (n 3) 11.
} 
Traxler ${ }^{50}$ definió a las personas adultas mayores como un grupo subordinado a causa de su edad, que ven vulnerados sus derechos por cuatro factores que intervienen en la percepción estereotipada y negativa en las sociedades occidentales generando edadismo: ${ }^{51}$ a) el miedo a la muerte, 52 b) el énfasis en un ideal joven, c) la productividad medida estrictamente en términos de potencial económico y d) la concentración en la institucionalización de las personas mayores. Vale la pena señalar que no todas las personas mayores se perciben a sí mismas como discriminadas en razón de su edad. Sin embargo, no deja de ser paradójico que a las personas mayores se les exijan más atributos comunes que a otros colectivos para reconocerles derechos. ${ }^{53}$

Esta definición que, solo considera el valor numérico de 60 años como factor para determinar quiénes son personas adultas mayores, sin intención probablemente, las sitúa como un grupo prima facie en situación de mayor vulnerabilidad y marginación social, dado los estereotipos y barreras sociales que se encuentran inmersos cuando abordamos la temática de la vejez o del envejecimiento; perpetuando, la discriminación estructural y desigualdad social. Debido que el imaginario social contempla una imagen de protección o sobreprotección a las personas mayores, situándolas solamente como un ser sujeto de protección e incluso un objeto de protección y se pretende subrogar su voluntad por la voluntad de un tercero, en algunos casos será la familia, la sociedad, las políticas públicas, entre otros.

Esta situación se ha visto exacerbada en la pandemia a través de las distintas normas legales que decretaron y prorrogaron la cuarentena focalizada de las personas adultas mayores. Situación legal que no sólo configuraba restringir su derecho de libre tránsito, sino que irradiaba en otros derechos tales como el derecho al trabajo, el derecho a la salud para tratamiento de otras enfermedades o malestares que no fueran COVID-19 y del desamparo psicológico, el derecho a la educación, entre otros, de los que nos ocuparemos más adelante. Sin tener en cuenta la condición primigenia de la persona adulta mayor como persona titular de derecho, con pleno goce y ejercicio de estos, y el debido respeto hacia su dignidad y bienestar.

\footnotetext{
50 Anthony J Traxler, Let's Get Gerontologized: Developing a Sensitivity to Aging (Southern Illinois University at Edwardsville, 1980).

51 Sandra Huenchuan ( $n$ 44) 90. (Definen el edadismo como el profundo malestar de los jóvenes y adultos frente a la vejez, debido que en el imaginario social esta etapa del ciclo de vida se caracterizaría por la inutilidad y finitud de la vida).

52 Robert Butler y Myrna Lewis, Aging \& Mental Health: Positive Psychosocial Approaches (C V Mosby Ed, 1973). (Señalan que el miedo a la muerte influye en el temor a la vejez, en la medida que las civilizaciones occidentales conciben la muerte como algo que está fuera del ciclo de la vida humana, es decir la confirmación de la no existencia).

53 Sandra Huenchuan (n 44) 91.
} 


\section{4.- Autonomía 54}

Como se ha señalado antes, justificar que "la vejez" tiene su "causa" en la edad de la persona, además de ser un postulado discriminatorio que sitúa en una posición de mayor vulnerabilidad a la persona adulta mayor, trae como consecuencia que aunque al amparo de la ley podría considerárseles titulares de los derechos que poseen el resto de los ciudadanos; en la realidad sólo van a poder gozar y ejercer en condiciones de igualdad cuando se amolden a los patrones que dictamine la sociedad. Situación difícil si se considera como características para ser sujeto de derecho la lozanía, juventud, la elaboración y realización de planes de vida en contextos donde no se les otorga oportunidad, entre otros, como un constructo de requisitos para disfrutar y ejercer derechos. Esta situación es similar por el que atraviesan las personas con discapacidad.

En ese contexto, DE ASIS relata que para la teoría clásica de derechos humanos "un sujeto moral supone considerar a hombres y mujeres como elementos esenciales del discurso moral, como sujetos racionales capaces de elaborar y proponer planes de vida y de llevarlos a la práctica, 55 sólo este sujeto moral es quién puede participar de la discusión moral." 56

Ciertamente, la teoría tradicional de los derechos se ha construido sobre una visión del ser humano como sujeto moral dotado de una serie de capacidades (capacidad de razonar, capacidad de comunicar, capacidad de sentir, capacidad de autogobernarse). Ejemplo de este presupuesto, es el pensamiento de KANT que señala "donde la persona tiene un valor incondicional, absoluto; es fin en sí misma, en suma: sujeto trascendente. Esta característica convierte a la persona en sujeto moral, objeto de predicación moral." 57

Bajo la concepción imperante social Kantiana se propugna aquella valoración de la persona fundada en la autonomía y racionalidad. Esta manera de reflexionar influirá en la construcción de

\footnotetext{
54 (El concepto de autonomía desde el enfoque de derechos humanos ha sido abordado en el mundo de la discapacidad, por lo que la perspectiva ayudaría a construir la autonomía en las personas adultas mayores), véase Patricia Cuenca Gómez, Los Derechos Fundamentales de Las Personas Con Discapacidad: Un Análisis a La Luz de La Convención de La ONU (Universidad de Alcalá, 2012). Se sugiere también, Mágaly Arredondo Bastidas, 'Discapacidad y capacidad jurídica en el ordenamiento jurídico del Perú a la luz de la Convención Internacional sobre los derechos de la persona con discapacidad' (Universidad Carlos III de Madrid, 2018) <https://earchivo.uc3m.es/bitstream/handle/10016/27702/TFM_MEADH_Magaly_Arredondo_ 2018. pdf?sequence=1\&isAllowed=y>.) Última fecha de acceso 20 febrero 2021 .

55 Rafael De Asís, Derechos humanos y discapacidad. Algunas reflexiones derivadas del análisis de la discapacidad desde la teoría de los derechos,(Dykinson, 2007) 36. 56 ibid 32.

57 Immanuel Kant, Fundamentación de la metafísica de las costumbres (Greenbooks editore, 2003).
} 
la propia teoría de los derechos humanos ${ }^{58}$ que se conecta en la actualidad con el tratamiento de la vejez, debido que si la persona adulta mayor no se ajusta a "los patrones de normalidad" se les excluye de pertenecer y participar de la sociedad "norma".

Como consecuencia de lo anterior, se establecen lineamientos de política paternalistas, 59 como regla general, en los menores de edad, las personas con discapacidad, adultos mayores, etc., ${ }^{60}$ basadas en la atribución de una falta de capacidades cognitivas y/o emocionales.

Esta situación no es considerada, por el grupo dominante de la sociedad no adulto mayor, como un comportamiento que violenta los derechos humanos de las personas adultas mayores. Por el contrario, se perpetúan, legitiman y justifican aquellas interferencias en la libertad personal.61 Un ejemplo muy frecuente, es la institucionalización prima facie de las personas adultas mayores que implica una forma de exclusión y estigma social.

La concepción tradicional de dignidad humana aunada a la capacidad de razonar, capacidad funcionar dentro de un cuerpomente-capaz y de preferencia "joven", es acogida por el Derecho, a través de la doctrina, sentencias y normatividad legal, esta última es la que se emitió en el Perú para establecer confinamiento focalizado para las personas adultas mayores en el tiempo de la pandemia.

Por eso, se debe cuestionar la idea de autonomía de la persona como un autogobierno, que excluye a las personas que no se encuentran dentro de un estándar de cuerpo-mente-edad-capaz.

58 De Asís (n 54) 32-33. ("el ideal de dignidad humana va asociado con el modelo de ser humano ilustrado, caracterizado por la posesión de una serie de rasgos asociados a patrones estéticos y éticos. (...) Así, la idea de dignidad humana - en ese contexto- se apoyó en un ser caracterizado por la capacidad y por el desempeño de un determinado papel social. Y ello se trasladó a la concepción de los derechos").

59 Javier Esquivel Pérez, La Persona Jurídica (UNAM, 1979) 34-35. (El autor refiere que respecto de la concepción Kantiana de persona que se introdujo en el mundo jurídico: Era la persona como un ente dotado de razón y voluntad libre. Una peculiaridad del concepto de persona, la cual se refleja en los usos jurídicos de la expresión, se advierte, sobre todo, en las propiedades que persistentemente se le adscriben: aptitud o capacidad moral, racionalidad, autonomía o dignidad).

60 Gerald Dworkin, Paternalism. (Ariel, 1990) 61. (El autor sostiene que "los menores de edad, los incapacitados legalmente, las personas con discapacidad psíquica o las personas que padecen ciertas enfermedades o se encuentran en una determinada situación clínica, carecen de ciertas capacidades cognitivas y/o emocionales que limitan su competencia para decidir acerca de que es lo mejor para ellas, o de qué manera proteger mejor sus intereses, $y$, por tal, motivo, requieren que alguien supla dicha carencia" El escenario descrito por el autor se asemeja la situación de las personas adultas mayores).

61 Theresia Degener y Aart Hendriks, 'The Evolution of a European Perspective on Disability Legislation' (European Journal of Health Law, 1994) 343, 346. (Los profesores argumentan que el hecho de que las personas con 'cuerpo-capaz' tiendan a percibirse ellas mismos como pertenecientes a la norma (o 'normales') perpetúa la situación de aquellas personas 'desventajadas' que tienen, bajo esta premisa, una 'capacidad disminuida' para producir). 
Debido que la autonomía, no debe ser considerada como un punto de partida - posición, en la que se fundamenta la teoría estándar de los derechos, sino como un punto de llegada. ${ }^{2}$ Así como la concepción de persona con cuerpo-mente-capaz es lo que ha imposibilitado el ejercicio de los derechos de las personas con discapacidad; la concepción de personas cuerpo-mente-edad-capaz imposibilita el goce y ejercicio de los derechos de las personas adultas mayores en vez de propiciar mecanismos para potenciar o alcanzar aquella autonomía. En esta idea ha argumentado DE ASIS "aunque en ciertos casos se encuentre más restringida no significa que deba ser anulada o ignorada, sino todo lo contrario; es en estos casos precisamente donde debe resaltarse el rol del Derecho en cuanto a la garantía de desarrollo pleno del grado de autonomía existente, por mínima que sea." 63 Por lo que, la autonomía es un fin y no existe un ejercicio independiente de autonomía, sino que el ser humano actúa o toma decisiones en base de sus experiencias o la de otros, consejos, familia, pareja, amigos, contexto social, laboral, emocional, etc. Precisamente, ETXEBERRÍA relata se deberá asumir honesta y empáticamente, en nuestra propia experiencia, esta condición de interdependencia y situar en ella, en toda su complejidad, al conjunto de las personas -con o sin discapacidad- (que sobrepasen o no lo 60 años a más), cada una a su manera. ${ }^{64}$ Por consiguiente, la autonomía es interdependiente y relacional 656667 y permite la participación de la persona adulta mayor en la sociedad buscando el goce y el ejercicio de derechos en un plano de igualdad entre todos, respetando su condición de sujeto de derecho y por tanto titular de goce y ejercicio de derechos.

Por ello, sería importante considerar en las políticas públicas, al igual que ocurre en el ámbito de la discapacidad, establecer un sistema de apoyos ${ }^{68}$ que no debería limitarse sólo al ámbito patrimonial, sino que debe proyectarse en todas las esferas de

62 María José Añón Roig, Necesidades y derechos: un ensayo de fundamentación (Centro de Estudios Políticos y Constitucionales, 1994) 267.

63 De Asís (n 54) 16.

64 Etxeberria (n 35) 36.

65 Esta idea ha sido ampliamente estudiada en el mundo de la discapacidad véase Anita Silvers y Leslie Pickering Francis, 'Thinking About the Good: Reconfiguring Liberal Metaphysics (or Not) for People with Cognitive Disabilities' (Metaphilosophy, 2009) 475-498.

66 También destacan esta idea 'Michael Bach y Lana Kerzner, A New Paradigm for Protecting Autonomy and the Right to Legal Capacity Advancing Substantive Equality for Persons with Disabilities through Law, Policy and Practice (2010).' 39 <https://www.lco-cdo.org/wp-content/uploads/2010/11/disabilities-commissionedpaper-bach-kerzner.pdf> Última fecha de acceso 27 febrero 2021.

67 Gerard Quinn, 'A Short Guide to the United Nations Convention on the Rights of Persons with Disabilities' (European Yearbook of Disability Law, 2009) 89-114 $<$ https://heinonline.org/HOL/Page?handle=hein.journals/euydisl1\&id=101\&div=\&co llection=>. Última fecha de acceso 19 febrero 2021 (El autor ha desarrollado ampliamente el concepto de autonomía relacional).

68 CIDHPM 2015, art. 30 (n 2). 
actuación de la persona adulta mayor, con el fin de promover y potenciar su autonomía, posibilitando el ejercicio de sus derechos humanos, respetando su voluntad y preferencias que le otorguen el igual reconocimiento como persona ante la ley.

\section{3.- LÍNEA De TIEMPO ENTRE EL 15 DE MARZO AL 27 DE DICIEMBRE DE 2020}

El Perú mediante Decreto Supremo No 044-2020-PCM, de fecha 15 de marzo de 2020, publicado en el Diario el Peruano, en adelante El Peruano, declaró el Estado de emergencia69 nacional y dispuso el aislamiento social obligatorio (cuarentena) para toda la población, por las graves circunstancias que afectan la vida de la Nación a consecuencia del brote del COVID-19, además suspendió y restringió el ejercicio de los derechos relativos a la libertad y seguridad personal, la inviolabilidad de domicilio, la libertad de reunión y de libertad de tránsito. El Ministerio de Salud (MINSA), mediante la Resolución Ministerial No 239-2020-MINSA de fecha 28 de abril del 2020 (44 días de cuarentena generalizada), aprobó el documento técnico: "Lineamientos para la vigilancia de la salud de los trabajadores con riesgo de exposición a COVID-19" e incluyó a las personas mayores de 60 años, dentro del grupo de riesgo.

Con el paso de los días, en el contexto del Estado de emergencia nacional y la cuarentena generalizada, se fueron flexibilizando las medidas para permitir la libertad de tránsito de los grupos que consideraban no estaban dentro del grupo de riesgo, en virtud de lo cual el MINSA mediante Resolución Ministerial No 2832020-MINSA publicado el 13 de mayo de 2020 en El Peruano (59 días de cuarentena generalizada), modificó el documento técnico de lineamientos, estableciendo dentro de la definición de grupos de riesgo a los mayores de 65 años, siendo que en la parte considerativa del acto resolutivo no se aprecia la fundamentación de la variación en el incremento de la edad, máxime sí en el Perú, la Ley de la Persona Adulta Mayor, Ley No 30490, en su artículo 2 señala "entiéndase por persona adulta mayor a aquella que tiene 60 o más años de edad".

Los días seguían trascurriendo, entre el aumento dramático del desempleo, la economía caía en picada, y dada la desesperación de la población de considerar que se vivía una cuarentena indefinida, el Perú mediante Decreto Supremo No 116-2020-PCM, publicado en el Peruano con fecha 26 de junio de 2020 (103 días de cuarentena generalizada), establece las medidas que debe seguir la ciudadanía en la nueva convivencia social, prorroga el Estado de emergencia y establece en su numeral 2.1 de su artículo 2 cuarentena

69 Constitución Política del Perú Act 1993, art 137, para 1.(Establece que el Presidente de la República con acuerdo del Consejo de Ministros, puede decretar el Estado de emergencia, en caso de perturbación de la paz o del orden interno, de catástrofe o de graves circunstancias que afecten la vida de la Nación). 
focalizada(...) "las personas en grupo de riesgo como los adultos mayores de sesenta y cinco (65) años (...) deberán continuar en aislamiento social obligatorio (cuarentena)(...)", así mismo, su artículo 8 señala que "Las personas en grupos de riesgo, (...) no pueden salir de su domicilio, y excepcionalmente lo podrán hacer siempre que requieran de atención médica urgente o ante una emergencia, así como para la adquisición de alimentos, medicinas y servicios financieros, en caso de no tener a ninguna persona de apoyo para ello. También pueden salir de su domicilio excepcionalmente para el cobro de algún beneficio pecuniario otorgado por el Gobierno en el marco de la Emergencia Nacional, para el cobro de una pensión en una entidad bancaria o para la realización de un trámite que exija su presencia física. (...)". Se constata de la revisión del Decreto Supremo que no se aprecia fundamentación de la cuarentena focalizada para las personas adultas mayores, por lo cual se entiende que la edad fue el parámetro para confinar en sus domicilios a las personas. ${ }^{70}$

En ese contexto, de cuarentena prorrogada y focalizada para las personas adultas mayores, el 03 de octubre del 2020 (202 días de cuarentena) mediante Decreto Supremo No 162-2020-PCM se modificó el Decreto Supremo No 116-2020-PCM específicamente su artículo $8^{\circ}$ en el que se agrega a las restricciones normadas la de "Las personas en grupos de riesgo no deben recibir visitas en su domicilio y deben evitar el contacto físico con las personas que se desplazan fuera del domicilio. Además, "(...) Las personas en grupos de riesgo, como los adultos mayores (...) podrán realizar caminatas con las siguientes restricciones: - A una distancia no superior de 500 metros respecto de su domicilio, en espacios abiertos y sin aglomeraciones. - La circulación se limita a una caminata de máximo 60 minutos de duración, 3 veces a la semana y, de preferencia, en las mañanas para evitar aglomeraciones con las salidas de otros grupos poblacionales. - Los adultos mayores dependientes o con discapacidad saldrán acompañados por una persona responsable de su cuidado." Este acto resolutivo en la parte considerativa señala que "la Dirección General de Intervenciones Estratégicas en Salud Pública del Ministerio de Salud, recomienda mantener el confinamiento de los adultos mayores como medida primordial". Es decir, las personas adultas mayores, luego de estar 202 días en situación de cuarentena exclusiva, por el hecho de tener una determinada edad, debían seguir en un confinamiento indefinido apartados de la sociedad e inmovilizados en sus domicilios, en el entendido que aquello era parte primordial de la estrategia de salud pública del Estado. ${ }^{71}$ Esta

70 CIDHPM 2015, art 1 (n 2). (... Los Estados Parte solo podrán establecer restricciones y limitaciones al goce y ejercicio de los derechos establecidos en la presente Convención mediante leyes promulgadas con el objeto de preservar el bienestar general dentro de una sociedad democrática, en la medida en que no contradigan el propósito y razón de los mismos).

71 ibid, arts $1,3,5,6,7,8,13,15$ y 30 (La situación descrita se enfrenta a los derechos de la Convención contemplados en su ámbito de aplicación y objeto, en 
situación de solo considerar la edad para excluir al grupo los va a situar en un contexto de mayor vulnerabilidad. Agravando su situación cuándo se les prohíbe "recibir visitas en sus domicilios para evitar el contacto físico de las personas que se desplazan fuera del domicilio", está disposición legal olvida la realidad peruana plasmada en la encuesta nacional de hogares (ENAHO) del INEI, informe técnico "Situación de la población adulta mayor"2 señala que, al primer trimestre del año 2020, en el 43,9\% de los hogares del Perú vive al menos una persona de 60 a más años. Es decir, en casi en la mitad de los hogares peruanos vive al menos una persona adulto mayor; por ende, en muchos casos los miembros de la familia no son "visitantes" sino conviven con la persona adulta mayor. Asimismo, sólo se les autoriza a "realizar caminatas a una distancia no superior de 500 metros respecto de su domicilio, máximo de 60 minutos y 3 veces por semana, lo mismo para las personas adultas mayores dependientes o con discapacidad." Estas disposiciones legales, que pretendieron ser medidas en beneficio para las personas adultas mayores, confundían a la población; por ejemplo: sí la medida sólo permitía distancias de caminatas no superior de 500 metros respecto del domicilio, se entiende que el parámetro para establecer dicha distancia es la dirección que se detalla en el adverso del documento nacional de identidad (DNI), sí eso es así, ¿qué sucede con las personas adultas mayores que no tienen DNI? que representan el $3,4 \%$ de la población adulto mayor en el Perú, ${ }^{73}$ ¿qué pasaba con las personas adultas mayores que su DNI no coincide con el lugar donde están habitualmente viviendo?, sea porque no cambiaron la dirección de su domicilio en el Registro Nacional de Identificación y Estado Civil (RENIEC), porque la cuarentena focalizada la vivieron en la casa de algún familiar, porque se les extravió el DNI, etc.; además, de ser detenidos por los miembros policiales que harían estos efectivos ¿ponerles multa?. Respecto del tiempo de duración y el periodo de la caminata de 60 minutos, 3 veces por semana ¿cómo se controla su cumplimiento?, ¿debería ir a la dependencia policial más cercana para indicar el día y la hora de inicio de la caminata, sirviendo de respaldo en una inspección policial que la persona adulta mayor cumple los parámetros establecidos en la ley?

sus principio generales, en el principio y derecho a igualdad y no discriminación por razones de edad, a la vida y a la dignidad en la vejez, a la independencia y autonomía, a la participación e integración comunitaria, a la libertad personal, a la libertad de circulación y al igual reconocimiento como persona ante la ley).

72 Instituto Nacional de Estadística e Informática, 'Informe-Tecnico-PoblacionAdulta-Mayor.Pdf' (INEI, junio

2020)<https://www.inei.gob.pe/media/MenuRecursivo/boletines/informe-tecnicopoblacion-adulta-mayor.pdf> Última fecha de acceso 26 febrero 2021.

73 ibíd., 6. 
Recordemos que, la Organización Mundial de la Salud (OMS), 74 diferencia tres conceptos fundamentales para informar a la población y contribuir con la elaboración de dispositivos legales y políticas públicas de los Estados "1) la cuarentena significa restringir las actividades o separar a las personas que no están enfermas pero que pueden haber estado expuestas a la COVID-19. El objetivo es prevenir la propagación de la enfermedad en el momento en que las personas empiezan a presentar síntomas, 2) el aislamiento significa separar a las personas que están enfermas con síntomas de COVID-19 y 3) el distanciamiento físico significa estar físicamente separado, recomendando mantener una distancia de al menos un metro con los demás". Al amparo de lo establecido por la OMS, se entiende la implementación de una medida sanitaria de cuarentena (aislamiento social) cuando a todas las personas de un determinado lugar geográfico se le impone la medida para evitar se propague el COVID-19, por otro lado, es contraproducente que se permita en un domicilio salir a unos y a otros no, debido que el riesgo de contagio de COVID-19 sigue siendo alto para las personas que no salieron de su domicilio. De los 37,830 fallecidos, ${ }^{75}$ un total de 26,520 son personas adultas mayores, que representa el $70 \%$, siendo de ese porcentaje el $68,41 \%$ son hombres adultos mayores y el $31,59 \%$ mujeres adultas mayores.

El Decreto Supremo No 162-2020-PCM, fue un detonante para escuchar las voces de las personas adultas mayores respecto del trato que venían recibiendo en la pandemia, se planteó una acción de amparo ${ }^{76}$ con la finalidad de revertir el Decreto Supremo; además, la Defensoría del Pueblo del Perú demandó modificar la cuarentena impuesta para personas adultas mayores "el confinamiento absoluto no solo afecta la dignidad de estas personas al desconocer su autonomía y su derecho al libre desarrollo de la personalidad, recogido en el artículo 2, inciso 1 de la Carta Magna, sino su salud física y mental, dados los efectos indeseados de esta reclusión."77 Por

74 Organización Mundial de la Salud, 'Preguntas y respuestas sobre la enfermedad por coronavirus (COVID-19)' (OMS, 12 octubre 2020)

<https://www.who.int/es/emergencies/diseases/novel-coronavirus-2019/advicefor-public/q-a-coronaviruses> Última fecha de acceso 26 febrero 2021.

75 Ministerio de Salud, 'Covid 19 En El Perú - Ministerio Del Salud' (MINSA, 3 octubre 2020) <https://covid19.minsa.gob.pe/sala_situacional.asp> Última fecha de acceso 10 octubre 2020.

76 El Economista, 'No es país para viejos: la discriminación contra los ancianos peruanos en la pandemia' (2020) EJLT

<https://www.eleconomistaamerica.pe/sociedad-eAm-

peru/noticias/10814520/10/20/No-es-pais-para-viejos-discriminacion-contra-losancianos-peruanos-en-la-pandemia.html> Última fecha de acceso 4 enero 2021.

${ }^{77}$ Defensoría del Pueblo, 'Defensoría del Pueblo demanda modificar confinamiento impuesto a personas adultas mayores' (Pronunciamiento 011/DP/2020, 02 octubre 2020) <https://www.gob.pe/institucion/defensoria-del-pueblo/noticias/305455defensoria-del-pueblo-demanda-modificar-confinamiento-impuesto-a-personasadultas-mayores> Última fecha de acceso 3 enero 2021. 
lo cual, mediante Decreto Supremo No 165-2020-PCM, publicado en el Peruano con fecha 08 de octubre de 2020, (207 días de cuarentena focalizada) se establece "En el caso de las personas en grupos de riesgo, como los adultos mayores de sesenta y cinco (65) años (...), se recomienda que permanezcan en sus domicilios; $y$ en caso requieran salir, lo hagan con el debido cuidado y siguiendo las medidas dispuestas por la Autoridad Sanitaria Nacional, que permitan evitar poner en riesgo su salud", sin derogar la cuarentena focalizada para las personas adultas mayores.

Hasta este punto, se aprecia que la cuarentena focalizada para las personas adultas mayores es el confinamiento especifico de este grupo poblacional sin contar con su consentimiento, por el contrario, ha sido planteado en un principio como una medida indefinida adoptada en contra de su voluntad, aunque con cierto consenso social que no observa la violación de los derechos humanos sino por el contrario ven la medida como una protección a la salud de las personas mayores, frente a la escasa prestación sanitaria que ofrece el país, lo cual refleja la situación de vulnerabilidad y discriminación por edad que sufren, dada su ubicación dentro de una estructura de dominación en relación a la población de personas no adultas mayores.

La amplia normatividad precitada que dispuso y prorrogó la cuarentena focalizada en salvaguarda del derecho a la salud contemplando únicamente evitar el contagio del COVID-19, no sólo trajo consigo la privación de la libertad de tránsito de la persona adulta mayor, sino que la medida irradió sobre otros derechos, entre los que podemos apreciar: derecho al trabajo, en el Perú las personas adultas mayores representan el $55,4 \% 78$ de la población económicamente activa (PEA) siendo mayor el porcentaje de hombres que de mujeres, $65,7 \%$ y $46,2 \%$, respectivamente. Asimismo, del total de hogares del país el $27,4 \% 79$ tiene como jefe de hogar a una persona adulto mayor. Es decir, más de la mitad de la PEA total en el Perú es persona adulta mayor de 60 y más años y que en un primer momento estaban considerados como grupo de riesgo y por tanto plausibles de la afectación de cuarentena focalizada; sin embargo, al necesitar la reactivación económica del país, se modifico de manera abrupta la edad del grupo de riesgo de 60 a 65 años; 80 situación que me permite decir que la edad sólo es una variable utilizada según las necesidades del grupo dominante que no es persona adulto mayor.

Al respecto del derecho a la salud, los dispositivos legales que decretaron y prorrogaron la cuarentena focalizada para las personas adultas mayores encontraron su fundamentación en evitar el contagio del COVID-19. Dada la precariedad del sistema sanitario del país, los

\footnotetext{
78 Instituto Nacional de Estadística e Informática, (n 71) 13.

79 ibíd., 2.

80 (En el Perú la edad mínima para jubilarse y poder tramitar la pensión de jubilación es de 65 años).
} 
establecimientos de salud dirigieron sus esfuerzos de manera exclusiva para la lucha contra la pandemia; sin embargo; se olvidó que el $82.3 \% 81$ de la población adulta mayor femenina presenta algún problema de salud crónico y en el caso de la población masculina, este problema de salud afecta al $72,9 \%$, personas que durante los primeros meses no encontraron atención en los hospitales, ni en sus programas médicos de control, recetas para el recojo de medicamentos, entre otros. ${ }^{82}$

Es parte fundamental para prevenir el contagio del COVID-19, el acceso al agua 83 que permita seguir con los protocolos de limpieza como el lavado de las manos, la desinfección de todos los comestibles que ingrese al hogar, entre otros; no obstante, en el Perú el 3.4\% de hogares con jefe de familia una persona adulta mayor en el área urbana no cuenta con este acceso; incrementándose tal diferencia de acceso al servicio en el área rural con $28,5 \%$, esta realidad social de desigualdad en el acceso a los recursos agrava la situación de vulnerabilidad de las personas adultas mayores, en estos casos no es la edad el factor que incrementa la posibilidad de contraer la enfermedad, sino la causa es la pobreza, la marginación, la exclusión social, que irradia en diferentes sectores como el acceso a los servicios básicos a la luz, al sistema de pensión, a las prestaciones o programas sociales, a la educación para contrarrestar la condición de analfabetismo 8485 que en el Perú representan al $15,0 \%$ de la población de 60 y más años de edad, situación que es tres veces más elevada en las mujeres adultas mayores que los hombres adultos mayores con el $22,4 \%$ y $6,8 \%$ respectivamente; también es el caso de situación de mayor vulnerabilidad del $46,1 \% 86$ del total de personas con discapacidad que son personas adultas mayores, siendo que de las mujeres con discapacidad el $52,3 \%$ son adultas mayores, mientras que en los hombres es el $40,4 \%$. En otras palabras, en el contexto de la pandemia bajo la lógica de pretender prevenir el contagio del COVID-19 en las personas adultas mayores, la mejor solución fue decretar y prorrogar el confinamiento focalizado de la persona adulto mayor, no previendo que la medida no sólo tuvo un impacto restrictivo del derecho a la libertad de tránsito, sino que estuvo relacionado a la limitación de otros derechos incrementando la situación de vulnerabilidad que viven las personas adultas mayores que son discriminadas por razón de edad. Asimismo, no se considero que, la OMS exigió a los Estados "garantizar que las personas mayores sean protegidas de COVID-19 sin estar aisladas,

\footnotetext{
81 Instituto Nacional de Estadística e Informática, (n 71) 9.

82 CIDHPM 2015 art. 19 (n 2). (Relacionado al Derecho a la salud).

83 ibid.art. 25. (En concordancia con el derecho a un medio ambiente sano (...) contar con servicios públicos (...)).

84 Instituto Nacional de Estadística e Informática, (n 71) 5.

85 CIDHPM 2015 art. 20 (n 2). (Vulnerando el derecho a la educación).

86 ibíd., 12.
} 
estigmatizadas, dejadas en una situación de mayor vulnerabilidad o sin poder acceder a las disposiciones básicas y a la atención social."87

Es a raíz del Decreto Supremo No 184-2020-PCM, publicado en El Peruano, el 30 de noviembre de 2020 (260 días de Estado de emergencia), que derogan los Decretos Supremos No 116,162 y 165-2020-PCM, que decretaron y prorrogaron cuarentena focalizada para las personas adultas mayores. Este dispositivo legal acoge lo establecido por la OMS y modifica la terminología de aislamiento social por aislamiento físico o corporal, se establece la responsabilidad personal y social en esta nueva etapa de convivencia, se brindan lineamientos de promoción y vigilancia de practicas saludables para todas las personas y se establece como única limitación al ejercicio del derecho a la libertad de tránsito la inmovilización social obligatoria de "todas las personas en sus domicilios desde las 00:00 hasta las 04:00".

De lo expuesto, en tiempos de pandemia se evidenció a través de los dispositivos legales que decretaron y prorrogaron la cuarentena focalizada para la persona adulta mayor, la discriminación por edad y por ende la privación de derechos de la persona adulta mayor, convirtiéndola solamente en un ser sujeto de protección, o en algunos casos, situándola en un escenario de rezago o abandono ${ }^{88}$; la finalidad pareciera contener la situación de contagio para impedir su asistencia a un sistema de salud insuficiente y desatendido de larga data; sin importar que se le despoje de su calidad de persona sujeto de derecho con pleno goce y ejercicio.

El 23 de diciembre de 2020 mediante Decreto Supremo No 0442020-RE, el Perú ratifico la Convención Interamericana sobre la protección de los derechos humanos de las personas mayores, aprobada por la Resolución Legislativa No 31090 del 16 de diciembre de 2020 con el objeto de promover, protege y asegurar el reconocimiento y el pleno goce y ejercicio, en condiciones de igualdad, de todos los derechos humanos y libertades fundamentales de la persona mayor, a fin de contribuir a su plena inclusión y participación en la sociedad. En virtud de lo expuesto, se espera que la Convención, sirva como un instrumento legal que conmine al Perú a respetar, garantizar y promover los derechos de la persona adulta mayor en igualdad y no discriminación por edad, permitiéndole alcanzar su autonomía, bienestar, un envejecimiento activo, saludable, por sobretodo una vida plena, vejez digna y su calidad de

\footnotetext{
87 Sandra Huenchuan, COVID-19: Recomendaciones generales para la atención a personas mayores desde una perspectiva de derechos humano (CEPAL, marzo 2020). https://www.cepal.org/es/publicaciones/45316-covid-19-recomendacionesgenerales-la-atencion-personas-mayores-perspectiva. Última fecha de acceso 10 febrero 2021. 9.

88 CIDHPM 2015, art. 2 (n 2). (La Convención define que el abandono es, la falta de acción deliberada o no para atender de manera integral las necesidades de una persona mayor que ponga en peligro su vida o su integridad física, psíquica o moral).
} 
sujeto

de

derecho.

\section{4.- PERCEPCIONES DE ALgunAS PERSONAS ADULTAS MAYORES EN EL PERÚ 89}

Con la finalidad de escuchar las voces de personas mayores se realizó una encuesta virtual denominada "Persona Adulta Mayor en el Perú en tiempo de pandemia (Covid-Derechos Humanos) y los resultados fueron los que se presentan a continuación:

Primera pregunta: Refleja que del total de personas encuestadas el $53 \%$ son mujeres y el $47 \%$ son hombres. Situación igual a la realidad peruana, como se mencionó antes, hay más mujeres que hombres en la población adulta mayor.

1) Usted es:

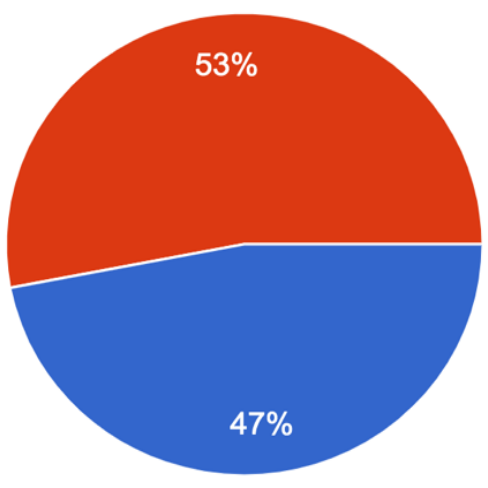

Hombre

Mujer

Fuente: Elaboración propia, sobre la base de la Encuesta (Covid-Derechos Humanos). Perú, del 10 al 27 de diciembre 2020.

Segunda pregunta: Hace referencia a los rangos de edad cronológico de las personas encuestadas se dividió en tres grupos: el $18,2 \%$ se encuentra en el rango de 60 a 64 años; el $67.6 \%$ en el rango de 65 a 79 años y el $14,2 \%$ de 80 a más años. Podemos apreciar dos indicativos; que el $18,2 \%$ fue aquel grupo de 60 a 64 años considerado en un primer momento como un grupo en situación de riesgo, pero el día 103 de Estado de emergencia les levantaron las restricciones juntamente con las personas no adultas mayores, con lo cuál este grupo, como ya se indicó, no fue comprendido dentro de la cuarentena focalizada que vivieron las personas adultas mayores de

89 (Encuesta en la que participaron 154 personas mayores peruanas, de fecha 10 de diciembre al 27 de diciembre 2020, la misma fue elaborada y procesada en google formularios y difundida por Whatsapp. Disponible en:

https://docs.google.com/forms/d/1hjQhpILX4ZkITPPrZhZDL9J7FoGK8wAmSc6fNm8FvU/edit\#responses (Última fecha de acceso 03 enero 2021)). 
65 años a más años; sin perjuicio que por voluntad propia mantuvieran el distanciamiento social y físico. Así mismo el grueso de la encuesta son las personas de 65 a 79 años, quiénes experimentaron la prohibición legal de la cuarentena focalizada al igual que las de 80 años a más.

2) Su edad está en el rango de:

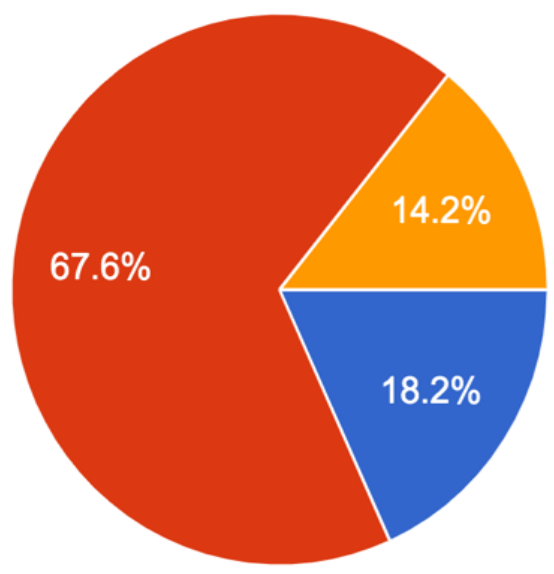

60 a 64 años

65 a 79 años

80 a más años

Fuente: Elaboración propia, sobre la base de la Encuesta (Covid-Derechos Humanos). Perú, del 10 al 27 de diciembre 2020.

Tercera pregunta: ¿Con quién vive? Se pretende saber si en la realidad se podía aislar del contacto físico y social a la persona mayor. La muestra total de personas encuestadas arroja que sólo el $8.8 \%$ vive sólo o sola; que el $18,2 \%$ vive con una persona mayor de 60 años, que el $18,2 \%$ con una persona menor de 60 años y el $54,7 \%$ vive con varias personas. Entonces en ese contexto, parecería que los dispositivos

legales que establecieron y prorrogaron el distanciamiento social focalizado para la persona adulta mayor con la finalidad evitar el contagio del COVID-19 no hubieran tomado en cuenta que la persona adulta mayor vive en un ambiente físico con más personas que no tuvieron restricciones de confinamiento, por lo que al salir y regresar a sus hogares pueden llevar la enfermedad a casa y contagiar a la persona adulta mayor que nunca salió de su domicilio. 
3) Vivo con:

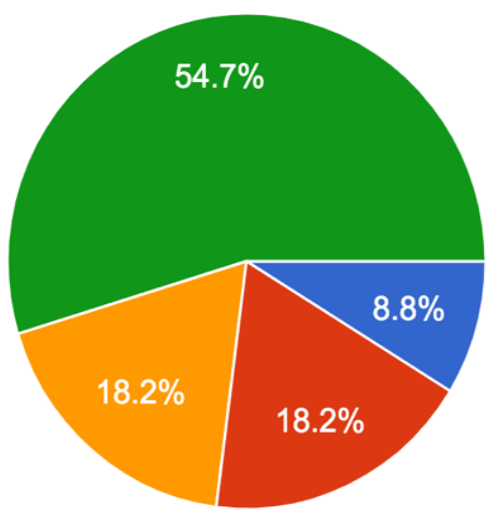

Vivo solo o sola

Con una persona mayor de 60 años

Con una persona menor de 60 años

Con varias personas

Fuente: Elaboración propia, sobre la base de la Encuesta (Covid-Derechos Humanos). Perú, del 10 al 27 de diciembre 2020.

Cuarta pregunta: ¿Usted se enfermó de COVID? El 4,1\% señaló que si, el $87,2 \%$ indicio que no y el $8.8 \%$ que no sabe si contrajo la enfermedad. Es interesante señalar la relación de estos resultados con la tercera pregunta, aunque el $72,9 \%{ }^{90}$ vive con personas no comprendidas en la cuarentena focalizada y por ende los riesgos de contagios serían más altos; las personas adultas mayores asumieron los cuidados pertinentes para proteger su salud. Lo que podría evidenciar que es la información de cuidados que cada quién asume y se responsabiliza, lo que evitaría o reduce el contagio y no el establecimiento de una cuarentena focalizada a priori.

4) ¿Se enfermó de Covid-19?
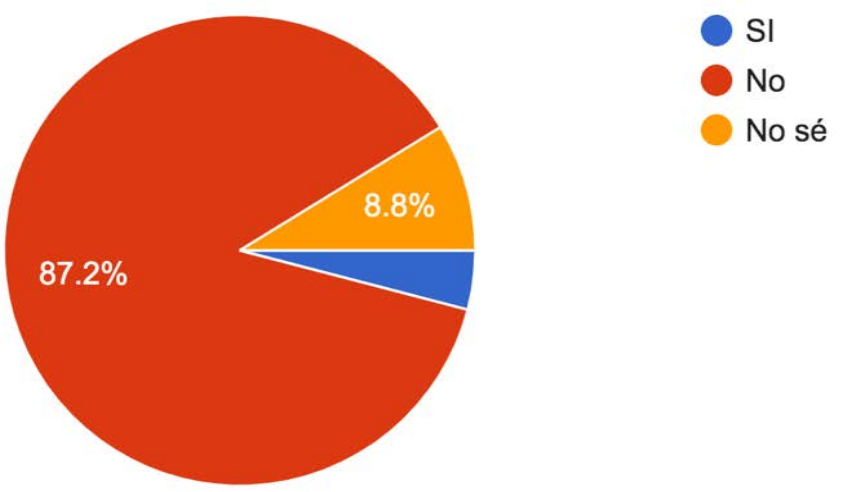

Fuente: Elaboración propia, sobre la base de la Encuesta (Covid-Derechos Humanos). Perú, del 10 al 27 de diciembre 2020.

90 (Se toma como referencia el porcentaje de personas mayores que respondieron que viven con una persona menor de 60 años (18.2\%) y quiénes viven con varias personas $(54.7 \%))$. 
Quinta pregunta: ¿Se ha sentido discriminado por su edad durante la pandemia? El $43 \%$ señala que no y el $52,7 \%$ indica que si. En esta pregunta directa la mayoría señala que sí se ha sentido discriminado. Es una pregunta difícil de contestar debido que nadie quiere ser o sentirse discriminado y reconocerse dentro de un grupo de exclusión social no es fácil, por eso se entiende, los márgenes reñidos que a lo largo de la encuesta iba variando ${ }^{91}$. Así mismo también debemos recordar el porcentaje de $18,2 \%$ de personas de 60 a 64 años quienes no tuvieron la cuarentena obligatoria focalizada y que probablemente no percibieron discriminación por edad.

5) ¿Se ha sentido discriminado por su edad durante la pandemia?

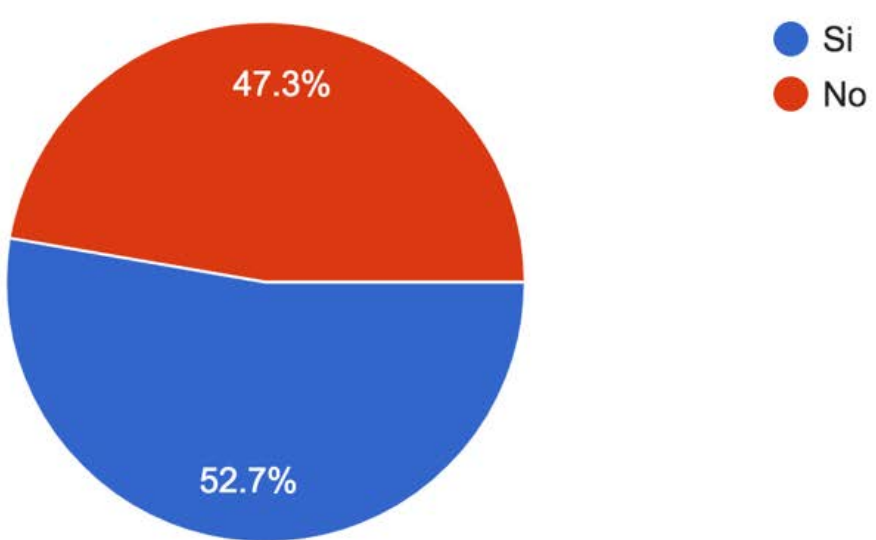

Fuente: Elaboración propia, sobre la base de la Encuesta (Covid-Derechos Humanos). Perú, del 10 al 27 de diciembre 2020.

Sexta pregunta: Sí la respuesta anterior fue afirmativa, indique ¿por quién se sintió discriminado? El 1,2\% señalo la familia, el 66,7\% el gobierno, el $13,6 \%$ por la información que trasmiten los medios de comunicación, el $11,1 \%$ la sociedad en general, el $7,4 \%$ otros. La pregunta estaba dirigida sólo aquellos que se sintieron discriminación en el contexto de la pandemia, esto es el $52,7 \%$ de la pregunta quinta, que se traduce en 78 personas adultas mayores; sin embargo, fue respondida por 81 personas adultas mayores, valga indicar que 2 personas señalaron dentro del rubro de otros, que nadie los discriminaba lo que representa el $2,4 \%$ del universo de $7,4 \%$. Por otro lado, existe un $1,2 \%$ de las personas que indicaron a quiénes consideran discriminan a las personas adultas mayores; sin embargo, estas personas se encuentran dentro de la población que señalaron no sentirse discriminadas en el tiempo de la pandemia en la pregunta quinta, lo que coincidiría con mi análisis realizado en aquella pregunta respecto a la negación de aceptar o reconocerse como una persona que es discriminada, dado los estereotipos que envuelve el

91 Sandra Huenchuan (n 44) 91. (En esta investigación se señala que no todas las personas mayores se perciben a sí mismas como discriminadas en razón de su edad). 
envejecimiento. En el rubro otro, fue un espacio para que las personas adultas mayores se expresen, encontrando las respuestas siguientes: queja por el deficiente servicio hospitalario e indolencia frente a su contagio del COVID-19 el cual pudo afrontar gracias a sus recursos económicos; persona que se sintió discriminada en un restaurante y en un bar; persona que se sintió discriminada en el ámbito laboral y finalmente una persona que se sintió discriminada por las limitaciones impuestas a los mayores.

6) Sí, la respuesta fue afirmativa. Indique ¿por quién se sintió discriminado?
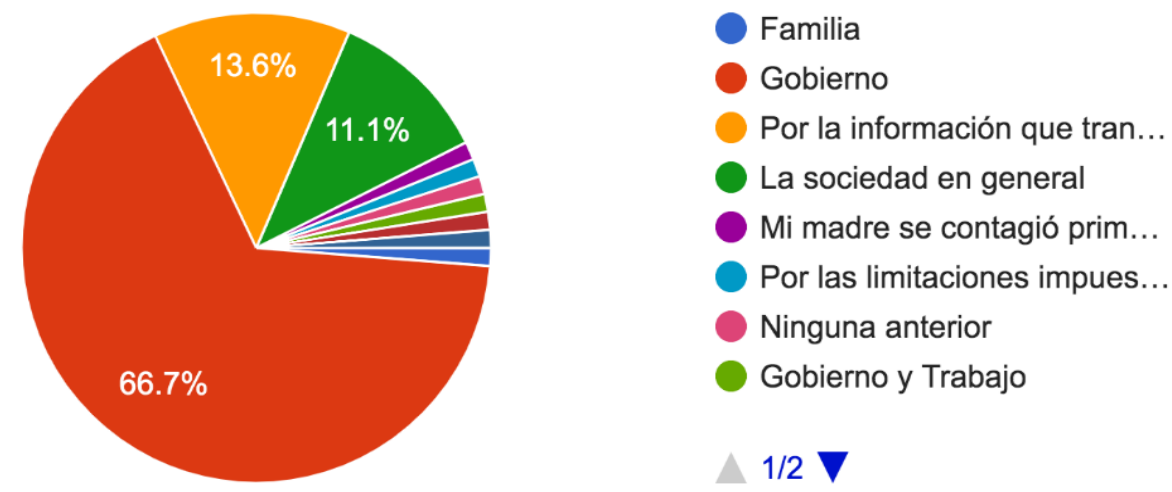

Fuente: Elaboración propia, sobre la base de la Encuesta (Covid-Derechos Humanos). Perú, del 10 al 27 de diciembre 2020.

Sétima pregunta: ¿Cómo se sintió cuándo el gobierno estableció que ninguna persona adulta mayor podría salir de su domicilio? El $38,8 \%$ sintió que el gobierno se preocupaba por su salud y le cuidaba, el $52 \%$ sintió que el gobierno no sabía como afrontar la pandemia y por eso lo confinó en casa; el $8.8 \%$ sintió otras cosas, y el $5,4 \%$ no sintió nada. El resultado del $52 \%$ del total de personas encuestadas, coincide con los resultados de la pregunta quinta cuando el $52,7 \%$ afirmó que se sentía discriminado por su edad durante la pandemia.

7) ¿Cómo se sintió cuándo el gobierno estableció que ninguna persona adulta mayor podía salir de su domicilio?
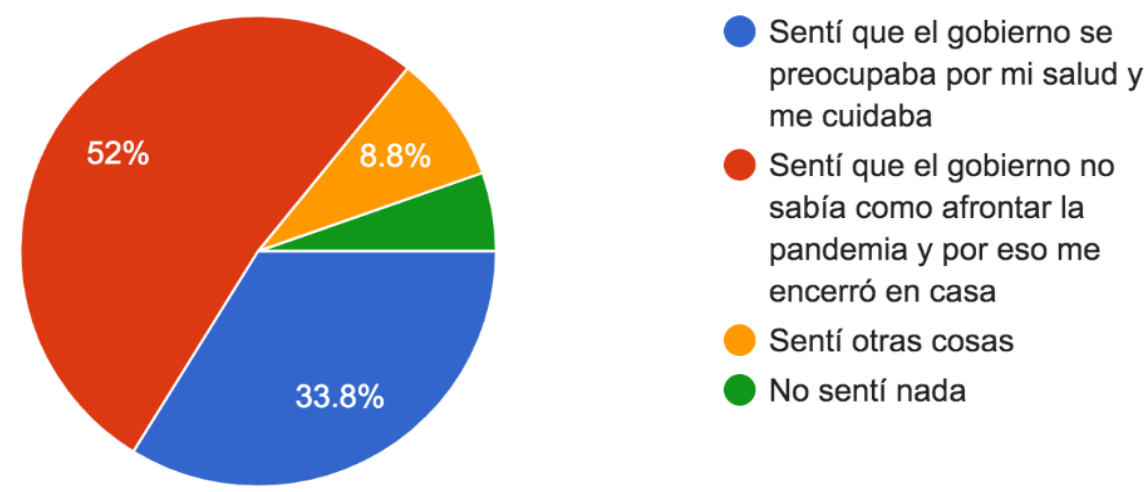

Fuente: Elaboración propia, sobre la base de la Encuesta (Covid-Derechos Humanos). Perú, del 10 al 27 de diciembre 2020. 
Octava pregunta: ¿Sabe usted la existencia de la Convención interamericana sobre la protección de los derechos humanos de las personas mayores?, el 50,3\% respondió que si y el 49,7\% manifestó que no. La respuesta mayoritaria del $50,3 \%$ sobre el conocimiento de la existencia de la Convención, coincide aproximadamente con los resultados obtenidos en las preguntas quinta y sétima respectivamente; es decir el $52,7 \%$ de las personas adultas mayores se ha sentido discriminado por su edad durante la pandemia y el $52 \%$ sintió que se les confinó en sus hogares porque no se sabía como afrontar la pandemia.

8) ¿Sabe usted la existencia de la Convención Interamericana sobre la Protección de los derechos humanos de las Personas mayores?

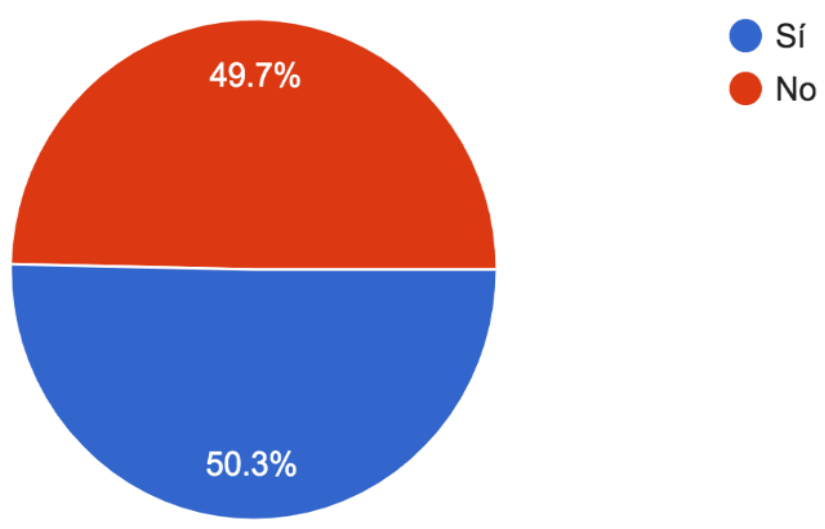

Fuente: Elaboración propia, sobre la base de la Encuesta (Covid-Derechos Humanos). Perú, del 10 al 27 de diciembre 2020.

Novena pregunta: En el contexto de la pandemia ¿Cómo cree usted qué hubieran sido las políticas públicas para las personas adultas mayores, sí el Perú hubiera acogido dicha Convención? El $20,4 \%$ considera que mejores porque no los hubieran confinado tanto tiempo en sus domicilios, el $3,4 \%$ señala que mejores porque los hubieran confinado más tiempo en sus hogares, el $53,1 \%$ considera que mejores porque se hubiera buscado una solución integral y heterogénea para las personas adultas mayores; el 5,4\% señala que ninguna de las opciones le satisface y el $17,7 \%$ responde que no sabe. El $53,1 \%$ de personas adultas mayores afirman que la Convención hubiera permitido buscar una solución integral y heterogénea, coindice aproximadamente con las personas adultas mayores que respondieron conocen la existencia de la Convención que es el $50,3 \%$. Por lo que si sumarían a los $53,1 \%$, los $20,4 \%$ que señalan una oposición al confinamiento focalizado, estamos hablando que el $73,5 \%$ de la población encuestada hubiera preferido otra medida que la cuarentena focalizada por razones de edad. 
9) En el contexto de la pandemia ¿Cómo cree usted qué hubieran sido las políticas públicas para las PAM, sí el Perú hubiera acogido la Convención?

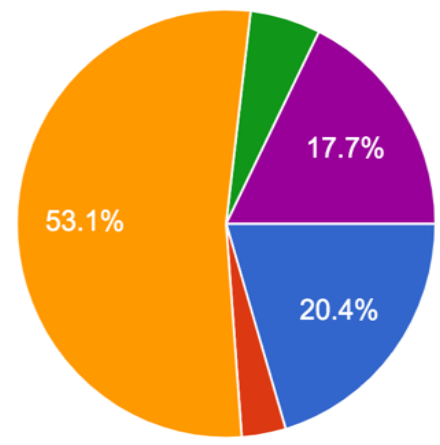

Mejores porque no nos hubieran confinado tanto tiempo en nuestros domicilio

Mejores porque nos hubieran confinado más tiempo en nuestros hogares

Mejores porque se hubiera buscado una solución integral y heterogénea para las personas adultas mayores

Ninguna de las anteriores

No sé

Fuente: Elaboración propia, sobre la base de la Encuesta (Covid-Derechos Humanos). Perú, del 10 al 27 de diciembre 2020.

\section{5.- A MODO DE CONCLUSIÓN}

La pandemia a causa del COVID-19, ha visibilizado aún más la imperiosa necesidad de erradicar los estereotipos respecto de la vejez, envejecimiento, de considerar a la salud solamente desde un componente biológico olvidando la esfera psicosocial. No envejecemos cuando cumplimos 60 o más años, el proceso de envejecimiento comienza desde el momento del nacimiento. Siendo continúo, dinámico, heterogéneo; por tanto, la persona que cruce el lumbral de determinada edad debe seguir siendo reconocida como una persona sujeto de derecho con pleno goce y ejercicio de los mismos, en un plano de igualdad y no discriminación por razones de edad, respetando su derecho a una vida digna, bienestar, derecho a la independencia para alcanzar su autonomía y con ellos la participación e inclusión en la sociedad.

La Convención adoptada en medio de la pandemia del COVID19, se espera sea un instrumento legal que conmine al Perú a respetar la universalidad, indivisibilidad, interdependencia e interrelación ${ }^{92}$ de todos los derechos humanos y libertades fundamentales de los que goza y debe ejercer la persona mayor, incluido el no verse sometida a discriminación fundada en la edad, debiendo incorporar el tema del envejecimiento en las políticas públicas y adoptar las medidas necesarias para su adecuada implementación.

Resulta importante, la investigación respecto de la temática relacionada a las personas adultas mayores en el ámbito de los derechos humanos, que permita contribuir con planes de gobiernos, políticas públicas, programas específicos, normas legales para visibilizar, proteger y garantizar los derechos de las personas

92 CIDHPM 2015 (n 2). (Establecido en el preámbulo). 
mayores, así como el cumplimiento de la Convención; asimismo, es necesaria la capacitación y formación de los gestores de gobierno, universidades, colegios, partidos políticos, asociaciones, familias, entre otros, para eliminar los estereotipos cuando se aborda el envejecimiento.

Finalmente, la pandemia nos debe impulsar asumir retos en la esfera del envejecimiento con una mirada de derechos humanos y escuchando a las personas mayores, en su calidad de titulares de derechos y con la obligación del Estado de hacer un Perú para todas las edades.

\section{6.- BIBLIOGRAFÍA}

Alba V., Historia Social de La Vejez (Laertes Editorial, 1992).

- - Paro y jubilación, envejecimiento prematuro en Gerontología y salud: perspectivas actuales (Biblioteca Nueva, 1997) 59-76.

Añón Roig M. J., Necesidades y derechos: un ensayo de fundamentación (Centro de Estudios Políticos y Constitucionales, 1994).

Araníbar P., Acercamiento conceptual a la situación del adulto mayor en América Latina (CEPAL, 2001).

Arber S. y Ginn J., Relación entre género y envejecimiento: Enfoque sociológico (Narcea Ediciones 1996).

Arredondo Bastidas M. M. 'Discapacidad y capacidad jurídica en el ordenamiento jurídico del Perú a la luz de la Convención Internacional sobre los derechos de la persona con discapacidad' (Universidad Carlos III de Madrid, 2018) $<$ https://earchivo.uc3m.es/bitstream/handle/10016/27702/TFM_MEADH_ Magaly_Arredondo_2018.pdf?sequence $=1$ \&isAllowed $=y>$.) Última fecha de acceso 20 febrero 2021.

Bazo M. T., La sociedad anciana (Centro de Investigaciones Sociológicas, 1990).

Blouin C., Tirado Rao E. y Mamani Ortega F. (eds), La situación de la población adulta mayor en el Perú: camino a una nueva política (Pontificia Universidad Católica del Perú Instituto de Democracia y Derechos Humanos 2018) <http://repositorio.pucp.edu.pe/index/handle/123456789/1335 91> Última fecha de acceso 26 febrero 2021.

Bury M., Envejecimiento, Género y Teoría Sociológica en Relación Entre Género y Envejecimiento (Narcea Ediciones, 1996) 33-54.

Butler R., 'Age-Ism: Another Form of Bigotry' en The Gerontologist (1969) 243-246.

Butler R. y Lewis M., Aging \& Mental Health: Positive Psychosocial Approaches (C V Mosby, 1973).

Comisión económica para América Latina y el Caribe, 'Panorama social da América latina 2012' (documento informativo) 2012. 
<https://repositorio.cepal.org//handle/11362/1246> Última fecha de acceso 26 febrero 2021.

Constitución Política del Perú, Act 1993.

Cuenca Gómez P., Los Derechos Fundamentales de Las Personas Con Discapacidad: Un Análisis a La Luz de La Convención de La ONU (Universidad de Alcalá, 2012).

Dabove M. I., 'Derecho y Multigeneracionismo: o los nuevos desafíos de la responsabilidad jurídica familiar en la vejez.' en Revista de Derecho de familia [2008] 39-54.

De Asís R., Derechos humanos y discapacidad. Algunas reflexiones derivadas del análisis de la discapacidad desde la teoría de los derechos,(Dykinson, 2007).

Defensoría del Pueblo, 'Defensoría del Pueblo demanda modificar confinamiento impuesto a personas adultas mayores' (Pronunciamiento 011/DP/2020, 02 octubre 2020) <https://www.gob.pe/institucion/defensoria-delpueblo/noticias/305455-defensoria-del-pueblo-demandamodificar-confinamiento-impuesto-a-personas-adultasmayores > Última fecha de acceso 3 enero 2021.

Degener $\mathrm{T}$ y Hendriks A, 'The Evolution of a European Perspective on Disability Legislation' (European Journal of Health Law, 1994) 343, 346.

Dworkin G, Paternalism. (Ariel, 1990).

El Economista, 'No es país para viejos: la discriminación contra los ancianos peruanos en la pandemia' (2020) EJLT $<$ https://www.eleconomistaamerica.pe/sociedad-eAmperu/noticias/10814520/10/20/No-es-pais-para-viejosdiscriminacion-contra-los-ancianos-peruanos-en-lapandemia.html > Última fecha de acceso 4 enero 2021.

Esquivel Pérez J., La Persona Jurídica (UNAM, 1979) 34-35.

Etxeberria X., La condición de ciudadanía de las personas con discapacidad intelectual (Universidad de Deusto, 2008).

Huenchuan S., Envejecimiento, Personas Mayores y Agenda 2030 para el Desarrollo Sostenible: Perspectiva Regional y de Derechos Humanos (Naciones Unidas ed, 2019) 73 <https://www.un-ilibrary.org/content/books/9789210586405> Última fecha de acceso 26 febrero 2021.

--, 'COVID-19: Recomendaciones generales para la atención a personas mayores desde una perspectiva de derechos humano (CEPAL, marzo 2020). https://www.cepal.org/es/publicaciones/45316-covid-19recomendaciones-generales-la-atencion-personas-mayoresperspectiva. Última fecha de acceso 10 febrero 2021.

Instituto Nacional de Estadística e Informática, 'Informe-TecnicoPoblacion-Adulta-Mayor.Pdf' (INEI, junio 2020)<https://www.inei.gob.pe/media/MenuRecursivo/boletine s/informe-tecnico-poblacion-adulta-mayor.pdf > Última fecha de acceso 26 febrero 2021. 
- - 'Nota de Prensa' (INEI, 25 agosto 2020) <http://m.inei.gob.pe/prensa/noticias/en-el-peru-existen-masde-cuatro-millones-de-adultos-mayores-12356/> última fecha de acceso 26 febrero 2021.

John Williams, 'An International Convention on the Rights of Older People?', Emerging Areas of Human Rights in the 21st Century: The Role of the Universal Declaration of Human Rights (Routledge edi, 2011).

Kant I., Fundamentación de la metafísica de las costumbres (Greenbooks editore, 2003).

Ley de la Persona Adulta Mayor No30490 Act 2006.

Leeson G., 'Prepared or Not, Latin America Faces the Challenge of Aging. Current History: Journal of Contemporary World Affairs' (Current History , febrero 2011) 75$80<$ https://www.ageing.ox.ac.uk/files/CurrentHistoryMarch\%2 0201.pdf> Última fecha de acceso 27 febrero 2021.

Bach M. y Kerzner L., 'A New Paradigm for Protecting Autonomy and the Right to Legal Capacity Advancing Substantive Equality for Persons with Disabilities through Law, Policy and Practice' (2010). <https://www.lco-cdo.org/wpcontent/uploads/2010/11/disabilities-commissioned-paperbach-kerzner.pdf> Última fecha de acceso 27 febrero 2021.

Villa M. y Rivadeneira L., 'El proceso de envejecimiento de la población en América Latina y el Caribe: una expresión de la transición demográfica' (Conferencia encuentro latinoamericano y caribeño sobre las personas de edad, Santiago de Chile, 8-10 setiembre 1999) <https://repositorio.cepal.org//handle/11362/34671> Última fecha de acceso 11 enero 2021.

Ministerio de Salud, 'Covid 19 En El Perú - Ministerio Del Salud' (MINSA, 3 octubre 2020) <https://covid19.minsa.gob.pe/sala_situacional.asp> Última fecha de acceso 10 octubre 2020.

Organización de Estados Americanos, Convención Interamericana sobre la protección de los derechos humanos de las personas mayores 2015. <http://www.oas.org/es/sla/ddi/tratados_multilaterales_intera mericanos_a-70_derechos_humanos_personas_mayores.asp $>$ Última fecha de acceso 26 febrero 2021.

Organización Mundial de la Salud, Preguntas y respuestas sobre la enfermedad por coronavirus (COVID-19) (OMS, 12 octubre 2020) <https://www.who.int/es/emergencies/diseases/novelcoronavirus-2019/advice-for-public/q-a-coronaviruses> última fecha de acceso 26 febrero 2021.

Osorio P., La Longevidad: Más Allá de La Bibliografia. Aspectos Socioculturales' (Universidad del País Vasco, 2006) 
<https://www.redalyc.org/pdf/765/76500603.pdf> Última fecha de acceso 26 febrero 2021.

Olivares-Tirado P., Dependencia de Los Adultos Mayores En Chile ( Departamento de Estudios y Desarrollo SIS- Superintendencia de Salud, marzo 2008) <https://www.supersalud.gob.cl/documentacion/666/articles4471_recurso_1.pdf> Última fecha de acceso 27 diciembre 2020.

Pérez Ortiz L., Las necesidades de las personas mayores en España: vejez, economía y sociedad (Madrid, Editores, 1998).

Quinn G., 'A Short Guide to the United Nations Convention on the Rights of Persons with Disabilities' (European Yearbook of Disability Law, 2009) 89-114 $<$ https://heinonline.org/HOL/Page?handle=hein.journals/euydis I1\&id=101\&div=\&collection=>. Última fecha de acceso 19 febrero 2021.

Rodríguez P., 'Investigación-Acción Participativa Como Estímulo a La Participación de Las Personas Mayores', en Voluntariado y Personas Mayores, (IMSERSO, Madrid, 1995).

Rose A.M., 'The Subculture of the Aging: A Framework for Research in Social Gerontology', en Older people and their social world: the sub-culture of the aging (1965).

San Roman T., Vejez y cultura hacia los límites del sistema (2da edición, 1990).

Silvers A. y Francis L.P., 'Thinking About the Good: Reconfiguring Liberal Metaphysics (or Not) for People with Cognitive Disabilities' (Metaphilosophy, 2009) 475-498.

Traxler A.J., Let's Get Gerontologized: Developing a Sensitivity to Aging (Southern Illinois University at Edwardsville, 1980).

United Nations, 'World Population Prospects' (Population Division United Nations, 2009 <https://population.un.org/wpp/> Última fecha de acceso 26 febrero 2021. 